\title{
17
}

\section{Can China's coal industry be reconciled with the environment?}

\section{Xunpeng Shi}

Coal provides 70 per cent of China's primary energy, therefore it is no surprise that China's air pollution is caused mainly by coal use. It has been reported that 85 per cent of the sulphur dioxide, 70 per cent of the smoke and 60 per cent of the nitrogen oxides emitted into the atmosphere in China come from the burning of coal (Wang and Feng 2003). The correlation between increased sulphur dioxide levels and coal consumption is above 95 per cent (He et al. 2002). Emerging concerns about climate change add further pressure to the use of fossil-fuel energy in general and coal in particular. As the world's second-largest consumer of energy, China's demand for energy will increase due to its growing population and the rapid increase in living standards. Given that China is the world's largest producer and consumer of coal, this issue is of great concern and importance to the global community.

To mitigate the environmental impacts of rapid economic growth, proposals to reduce waste-gas emissions (WGEs) usually include changing the economic structure, reducing energy intensity and enforcing waste-gas treatment (Liang and Zhou 2008). These measures often lead to reductions in use of energy, particularly coal. Globally and in China-a country with serious environmental pollution, a growing demand for a clean environment, serious concerns about climate change and coal-dominated air pollution-many people think that the coal industry has no future; in China, the coal industry is sometimes called xiyang gongye ('the sunset industry') (Coal Enterprise Management 2001). 
Many others are, however, arguing that there is a promising future for the coal industry in general and the Chinese industry in particular (Coal Enterprise Management 2001; Li 2003; Shi 2003, 2006; Wang 1999; Huang 2001). A key argument for this is that there is a decreasing trend of pollution emissions per unit of coal, or emission intensity, and therefore the coal industry can harmonise with the environment (Shi 2003, 2006). The argument suggests that environmental pressure will induce innovations in clean-coal technologies. The ultimate level of cleanliness will be decided by technical progress and socioeconomic conditions. Many coal experts are also arguing that coal can be a truly clean energy; ${ }^{1}$ however, no empirical evidence has been provided with which to examine this issue.

This study will test the evolving pattern of coal emissions intensity using industry WGE data for the period 1996-2006. The focus on industrial WGEs only is appropriate because industrial pollution plays a dominant role in total emissions (Table 17.1): for example, 86 per cent of total sulphur dioxide emissions and 79 per cent of total smoke emissions came from industrial sources in 2005 (SEPA various years). The study will focus on three air pollutants: sulphur dioxide emissions ( $\mathrm{SO}_{2}$ ), industrial smoke emissions (Smoke) and dust emissions (Dust). Carbon dioxide emissions, although a popular topic and probably significant, are not included because there are no current data for them. Furthermore, although greenhouse gas emissions are a major concern, the most immediate environmental phenomenon is local ambient air pollution, which is predicted to cause health damage worth 13 per cent of China's gross domestic product (GDP) by 2020 (OECD 2007, cited in IEA 2007). The literature (Ang and Pandiyan 1997; Ang et al. 1998; Wang et al. 2005; Wu et al. 2006) often infers carbon dioxide emissions by assuming a constant emission intensity for each fuel, including coal-something that will be challenged in this study.

The rest of this chapter is organised as follows. The second section provides a general background of China's environmental regulations for air pollution. The third section introduces the two study methods, followed by a section describing the data. The fifth section presents the empirical results and the sixth section discusses some technical issues. The last section concludes the chapter.

\section{Environmental regulations and the coal industry}

The Chinese government attaches great importance to environmental protection. The first national conference on environmental protection in 1973 set up the Environmental Protection Office under the State Council and stipulated the 'three synchronisations' system. ${ }^{2}$ The 1978 Chinese Constitution stated the central government's intention to protect and improve the environment, and to 
prevent and control pollution. Environmental protection was declared one of two Chinese 'national fundamental policies' in 1983. ${ }^{3}$ The Environmental Protection Law (Trial Implementation) was promulgated in 1979, which proposed the Environmental Impact Assessment (EIA) System and the polluter-pays principle. It was revised and enacted officially in 1989. Between 1949 and 2005, China legislated nine environmental laws and 15 resource-protection laws, it formulated and promulgated more than 50 administrative regulations and 660 ministerial and local environmental rules and regulations related to environmental protection (State News Office 2006).

With the development of environmental protection, the control of WGEs is evolving. The National Ambient Air Quality Standards were published in 1982, specifying standards for air pollutants such as sulphur dioxide, total suspended particulate matter (TSP), nitrogen oxides and carbon (SEPA 1982). In 1998, the Chinese government (State Council 1998) approved the delimiting of two 'control areas' (the 'sulphur dioxide control area' and the 'acid rain control area'), which led to a significant improvement in environmental quality (State News Office 2006). In June 2007, China's State Council approved a national plan to address the challenges of climate change, symbolising that climate change was becoming increasingly important on China's national policy agenda (NDRC 2007a).

Some financial incentive mechanisms for reducing air pollution are already in place. Tax reductions or exemptions are given to enterprises engaged in environmental protection (State News Office 2006). A pollution levy system based on the polluter-pays principle was implemented nationally in 1982. Between 1995 and 2005, the collection of sulphur dioxide discharge fees was expanded to include all related enterprises and the rate was raised from 0.2 to 0.63 yuan per kilogram (State News Office 2006). The rate has been increased further in some provinces. ${ }^{4}$

Massive pollution control measures have also been implemented: 84,000 small enterprises that caused serious waste and pollution were closed during the ninth Five-Year Plan (1996-2000); eight resource pollution-intensive industries, including iron and steel, cement, electrolytic aluminium and coking, were restructured; and the construction of more than 1,900 projects was either stopped or postponed (State News Office 2006).

With these efforts in place, the control of air pollution has been considerable. The volume of removed industrial sulphur dioxide reached 10.9 million tonnes in 2005, up from 2.34 million tonnes in 1998, while the volumes for smoke and dust reached 205.87 million tonnes and 64.54 million tonnes respectively in 2005 , compared with 86.70 million tonnes and 30.98 million tonnes in 1998. The 
amount of industrial sulphur dioxide, industrial smoke and dust discharged in the generation of one unit of GDP in China in 2004 dropped by 42 per cent, 55 per cent and 39 per cent, respectively, from the levels in 1995 (State News Office 2006).

With increasing implementation of environmental regulations in China, the future of coal is under suspicion as it is the most polluting of the fossil fuels and the key source of pollution in China. After 1998, Chinese coal production experienced a three-year depression ${ }^{5}$ and state-owned coal mines (SOCMs) suffered heavy deficits, which led to increasingly widespread pessimism about the industry's future (Shi 2003, 2006; Coal Enterprise Management 2001). Amid the concerns and dire predictions about the future of the coal industry, coal production and consumption increased dramatically after 2000.

Although coal consumption has been soaring in recent years, dust and smoke emissions are declining. There has been a slight increase in sulphur dioxide emissions, but the speed of the increase is far slower than that of coal consumption. Coal consumption increased nearly 92 per cent between 1997 and 2006, yet emissions of sulphur dioxide increased only slightly, by 10.35 per cent, during the same period.

\section{Figure 17.1 Coal industry development and air pollution emissions,} 1997-2006

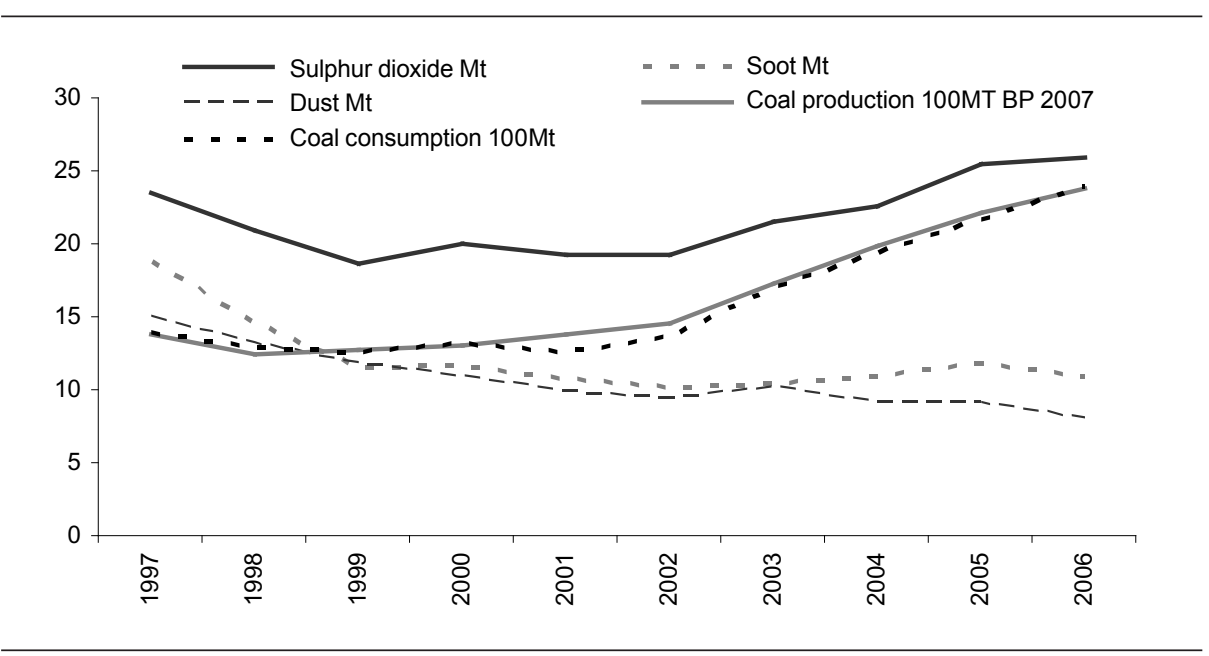

Sources: State Environmental Protection Administration (SEPA), 1996-2006. State Public Release of Environmental Protection, State Environmental Protection Administration; National Bureau of Statistics (NBS), various years. China Statistical Yearbook, China Statistics Press, Beijing. To avoid the underreporting of production due to the mine closure policy, the production data were extracted from British Petroleum (BP), 2007. BP Statistical Review of World Energy. 


\section{Emission intensity trends}

Most studies of emission intensity focus on carbon dioxide emissions (see Ang and Zhang 2000 for a review). Only a few studies address sulphur dioxide emissions (Lin and Chang 1996; Shrestha and Timilsina 1997; Viguier 1999); among these, two (Shrestha and Timilsina 1997; Viguier 1999) address the emission intensity of individual energy sources, including coal, as a constant over time and focus only on changes in the energy mix - that is, the inter-energy composition of oil, gas, coal and non-fossil fuel energies. Lin and Chang (1996), however, find a continuous decrease in pollution intensity and attribute it to substitution for imported low-sulphur coal and 'desulphurisaton' of fuel oil, in the case of Taiwan. No study has, however, been done from the perspective of a clean future for fossil-fuel energy, and coal in particular. Emission intensities for smoke and dust have also not been addressed.

In this section, two alternative methodologies are presented to test the hypothesis that coal emission intensity is declining. The econometric technique is used to test the emission intensity of coal with a focus on a long-term dynamic aspect of this intensity. The index decomposition (ID) approach is used to identify various factors that determinate the final emissions and their individual contributions.

\section{The fixed-effects panel data model}

The first method to be used is a fixed-effects panel data model, which, together with econometric data, will test the general trend of emission intensity-that is, at time $t$, in province $i$, the $j t h$ WGE, is

$$
W G E_{i t j}=\beta_{0}+\left(\beta_{1}+\beta_{2} T\right) \text { FuelC }_{i t}+\left(\beta_{3}+\beta_{4} T\right) M a t C_{i t}+\beta_{5} X_{i t}+\alpha_{i j}+u_{i t j}
$$

in which WGE denotes pollutant emissions; FuelC and MatC denote consumption of fuel coal and material coal, respectively; $T$ is a general time trend; $\alpha_{i j}$ is the province-specific effect in the case of the $j$ th pollutant; $u_{i t j}$ is a normally distributed error term; $j=1,2,3$ is sulphur dioxide $\left(\mathrm{SO}_{2}\right)$, smoke and dust respectively. Of particular interest are the signs of $\beta_{1}$ and $\beta_{4}$. If $\beta_{2}$ or $\beta_{4}$ were significantly negative, we would find evidence of decreasing emission intensity. Due to different characteristics between fuel and material coal in different cases of air pollution, $\beta_{2}$ and $\beta_{1}$ are expected to be different.

$X$ is a vector of exogenous variables such as population (POP), average GDP and environmental regulation and implementation variables, to investigate the impact of various exogenous variables on the emissions function. The more 
stringent the environmental regulation and enforcement, the less are the WGEs because polluters are more likely to be punished or charged. Several variables have been used to test the impacts of legislation and enforcement. Bao and Peng (2006) used the number of cumulative environmental standards issued by provincial governments to measure the effect of environmental policy on emissions, but they failed to find a positive role for such policies on air pollution. The compliance cost was used as a proxy for enforcement based on the assumption that the two had a positive correlation (Gray 1987). Gray (1987) uses the number of penalties (fines) to study safety regulations. In this study, the cumulative number of environmental standards (Standard) is used to approximate the effect of legislation; the operating cost of wastegas treatment equipment (Cost) is used to approximate the stringency of enforcement. Environmentally related research and development expenditure $(R \& D)$ is included to measure the technology progress effect, as in Bao and Peng (2006). The GDP deflator is used on all monetary value terms to the 1996 constant price of 10,000 yuan.

\section{Decomposed factors determining emissions}

Since most WGEs in China come from the consumption of fuel, they are affected by factors such as economic structure, energy intensity, economic development and population growth. It would be helpful if the WGE changes were broken down into various factors. Index decomposition has been a popular tool in the past 40 years to assess quantitatively various factors affecting WGEs and energy demand. Ang and Zhang (2000) found that it had been applied in at least 124 studies by 2000. This approach has advantages over econometric estimations in that it can apply to small samples and does not need any assumptions about distribution. This method is applied initially to studies of industrial energy decomposition and energy demand. Torvanger (1991) was the first to apply the index-decomposition methodology to study energy-related gas emissions, and was followed by many other studies (Ang and Zhang 2000). The types of gas emissions studied included carbon dioxide, sulphur dioxide and nitrogen oxides. Compared with energydemand decomposition, the emission decomposition includes more factors, including sectoral fuel share and fuel emissions (Ang and Zhang 2000).

The Laspeyres method and the Divisia index (LMDI) are the most frequently used and preferred decomposition methods in energy-induced gas emission studies (Ang and Zhang 2000). In this study, the LMDI approach is applied because it has the time-reversal property of an ideal index and can perform a perfect decomposition and accommodate zero values in the data set, which is preferable to the refined Laspeyres method (Ang and Zhang 2000). 
Two kinds of indicators are often used in the index-decomposition studies of energy and environmental issues. The first is a quantity indicator such as total energy consumption or total gas emissions; the other is a ratio or index indicator, including aggregate energy intensity and aggregate gas emissions intensity (Ang and Zhang 2000). In this study, we chose the first, with total WGE as the indicator. Total consumption of coal (TC), fossil-fuel energy (FE) and energy consumption (TE) are evaluated at 10,000 tonnes of standard coal equivalent (SCE), which will avoid heterogeneity of different coal qualities. $Y$ is GDP and $P$ is population. The explicit introduction of coal into the emissions function is an extension of the previous literature.

Similar to Wang et al. (2005), the WGE is expressed as an extended Kaya Identity (IPCC 2001; Kaya 1990)—-that is

$$
W G E_{i}=\frac{W G E}{T C} \frac{T C}{F E} \frac{F E}{T E} \frac{T E}{Y} \frac{Y}{P} P=E C F I G P
$$

in which $i$ is the type of emission, including sulphur dioxide, smoke and dust; $E$ is the mean $W G E$ emission intensity of coal (which is the core interest of this study); $C$ is the share of coal in total fossil-fuel energy, or the fossilfuel composition factor; $F$ is the share of fossil-fuel energy in total energy consumption, or the energy component factor; $I$ is energy intensity; and $G$ is GDP per capita.

As shown by Wang et al. (2005), using the LMDI (Ang et al. 1998), the difference in WGEs between two periods, $t$ and $T$, can be expressed as

$$
\begin{aligned}
& \Delta W G E_{t T}=W G E_{i T}-W G E_{i t}=E_{i T} C_{i T} F_{i T} I_{i T} G_{i T} P_{i T}-E_{i t} C_{i t} F_{i t} I_{i t} G_{i t} P_{i t} \\
& =\sum_{K} \Delta W G E_{K-\text { effect }}, K=E, C, F, I, G, P
\end{aligned}
$$

In which, the K-effect on emission reduction is

$$
\Delta W G E_{K-\text { effect }}=L\left(W G E_{i t}, W G E_{i T}\right) \operatorname{In}\left(K_{T} / K_{t}\right)
$$

in which

$$
L(x, y)=(x-y) / \operatorname{In}(x / y)
$$


We also define the case of no change in emission intensity (Non-CEI) as the basis for comparison with the current study. Following Equation 3, the Non-CEI of WGEs can be derived by dropping the emission intensity effect as

$$
\text { Non-CEI }=\sum_{K} \Delta W G E_{K-\text { effect }}, K=C, F, I, G, P
$$

\section{Data description}

We study the time trend and determinants of WGEs from coal consumption using China's provincial panel data from 1996-2006. We chose this period because data for coal consumption broken down to combusting and material inputs were available only from 1996. Data for three kinds of air pollutants, consumption of two kinds of coal and various environmental variables were drawn from the various issues of the China Environmental Yearbook (SEPA various years). Table 17.1 provides a summary.

The data for national total coal production (in physical quantity and in standard coal equivalent), energy consumption and its mix, GDP and its deflators and population are drawn from the various issues of the China Statistical Yearbook (NBS various years). The national GDP data are deflated to 1996 constant prices. When there is more than one set of data, we prefer the most up-to-date one because China's State Statistical Bureau significantly adjusted energy-use data in 2006. A history of the evolution of these aggregate data is shown in Figure 17.2.

\section{Empirical estimation and analysis of results}

Econometric results: evidence from the industrial sector

As in the literature (Shadbegian and Gray 2006), the 'seemingly unrelated regressions' (SUR) model is employed to allow for correlations in the residuals across equations for the three air pollutants. SUR is used because factors such as environmental legislation, environmental policy and changes in enforcement will affect the outcomes for all air pollutants simultaneously. To accompany both the fixed-effects, or unobserved regional heterogeneity and SUR, we use a dummy variable version of the SUR model-that is, we create 31 dummy variables for 31 provinces and include 30 of them into the regression functions to accompany the fixed effect, or unobserved regional heterogeneity. Estimation results of the SUR model are shown in Table 17.2.

The results demonstrate that there is a significant (at the 1 per cent level) decline in emission intensity in the case of material coal. For fuel coal, there is 


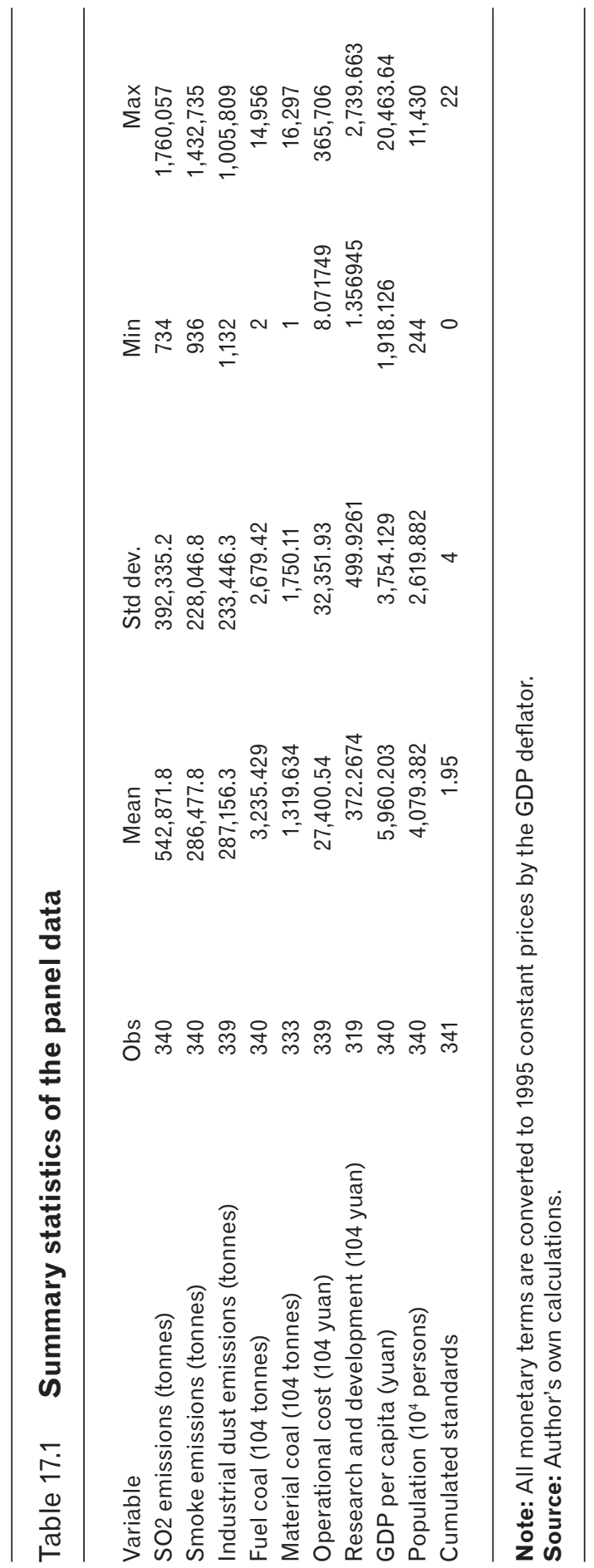




\section{Figure 17.2 Historical changes in the five factors in the index- decomposition study, 1990 - 2006}

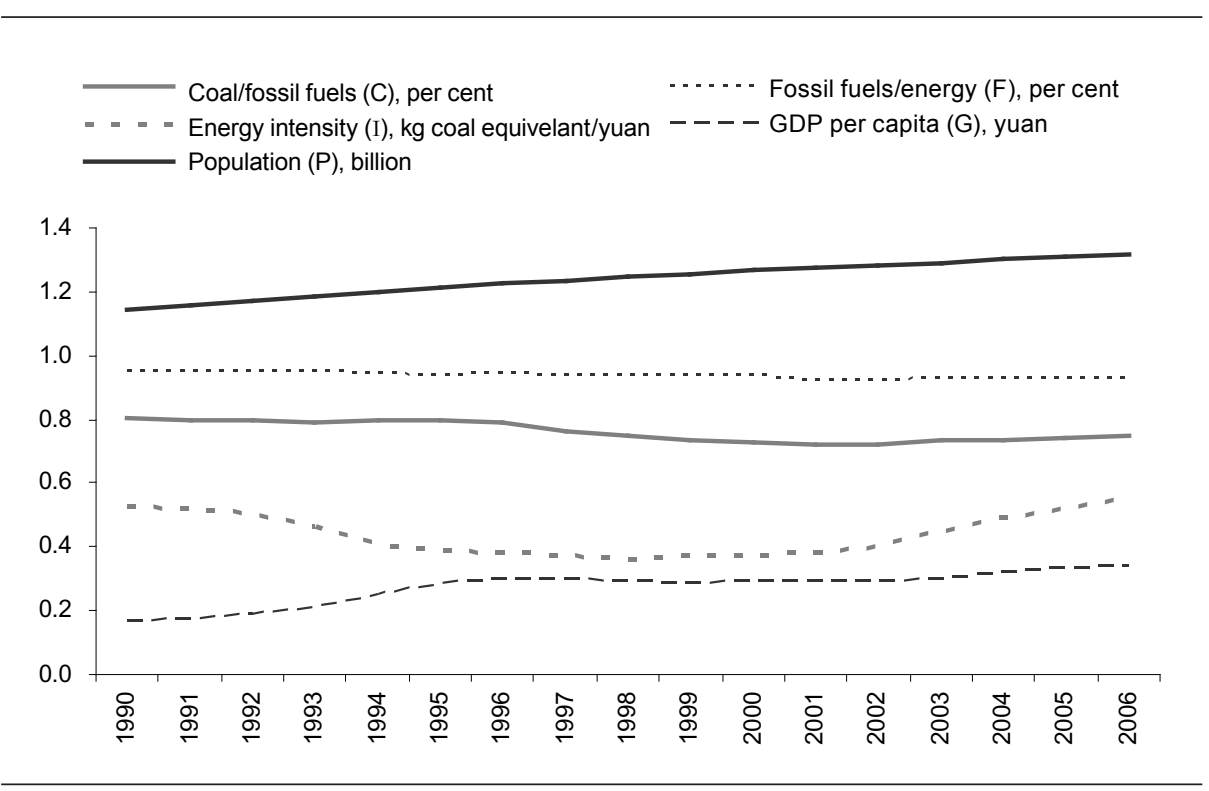

Note: Units are rescaled to fit into the same frame.

Source: Author's own calculations.

also a significant (at the 1 per cent level) decline in emission intensity, except in the case of dust. We can calculate the emission intensity of these two kinds of coal by taking the partial derivative of WGE with respect to coal consumption. To test the robustness of this conclusion, in the second specification, we remove regulatory and economic variables and find the conclusion unchanged (Table 17.2).

We can also calculate the time when overall emission intensity will decline to zero, which is called the 'zero emissions point' (Table 17.3).

The decline in emission intensity is unlikely to be linear in time, as assumed here, because that would lead to negative emission intensity. The actual decline is likely in a non-linear pace with diminishing rate. This hypothetical zero emissions point, however, provides a relative comparison among different cases in terms of the two kinds of coal and the three types of air pollution emissions. It can be seen that in the case of sulphur dioxide, the zero emissions point for material coal will be reached more quickly than that for fuel coal. The reasons for this could be: 1) economic, as material-coal users can reduce WGEs with a 


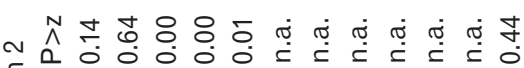
ㅇำ 䙳

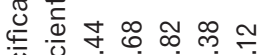

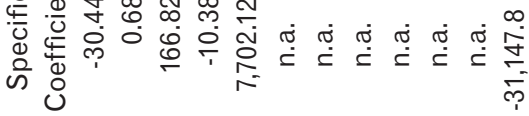
녹

ค -

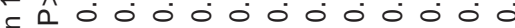
웅

芹

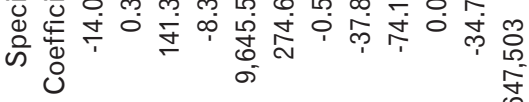

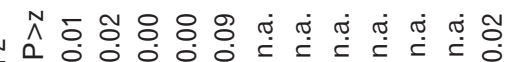

으

苞

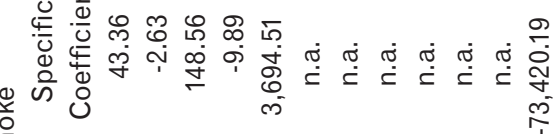

है

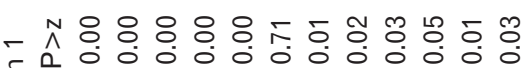
ㄷำ

몽

雚

产 ซூ की

๘

苞

造

N

둥

$\frac{0}{\frac{0}{\sigma}}$

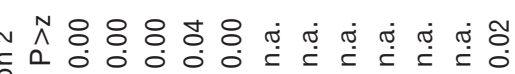
음

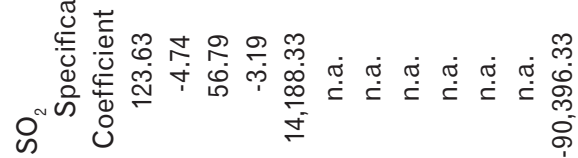

ก थी

ᄃ슨 름

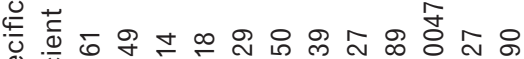

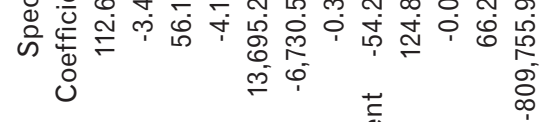
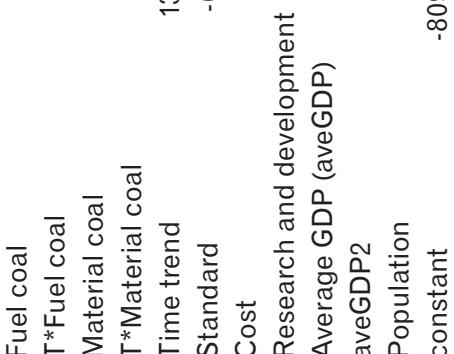

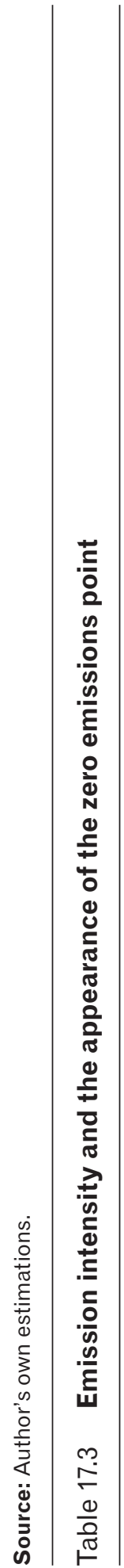

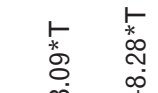

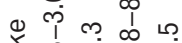
○ ஸे

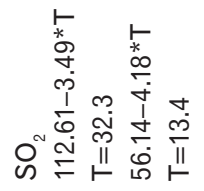

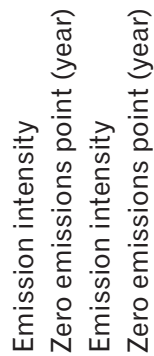


lower marginal cost than fuel-coal users; or 2) technical, as material-coal users, usually chemical producers, can produce by-products, such as sulphur, from WGEs. The second reason could also explain why sulphur dioxide has the shortest zero emissions point for material coal among the six cases.

Legislation, approximated by cumulative environmental standards, has a significant impact on reducing sulphur dioxide emissions, while increased use of WGE-treatment machines can lead to a reduction of all three air pollutants. The variable of cumulative environmental standards is significant only at the 1 per cent level in the case of sulphur dioxide. Implementation, approximated by the operating costs of WGE-treatment machines, is significant for smoke and dust at the 5 per cent level and for sulphur dioxide at the 10 per cent level. The significance of the effect of regulations on the removal of sulphur dioxide could be the reason why environmental regulations have led to the increased application of desulphurisation equipment. It could also be due to the fact that environmental regulations have spurred a demand for low-sulphur coal, as noted by Darmstadter (1999) in the US case. Whatever the reason, we can conclude that implementation is more important than legislation alone. The insignificant effect of legislation could also be due to the fact that much environmental legislation is not related to air pollution and this variable is therefore not a good proxy for this study.

The technological effect, approximated by environmentally related research inputs, is, however, negative and significant at the 5 per cent level in all three emissions cases, which is consistent with the literature (Bao and Peng 2006). This demonstrates that technical change has played a role in reducing emissions; therefore, investment in environmentally related research in general, and in clean-coal technology in particular, is one way to reduce air pollution.

Our findings about the pollution-income relationship are not consistent with the literature. Bao and Peng (2006) found that all three air pollutants-sulphur dioxide, smoke and dust-had an inverted-U shaped relationship with economic growth. Grossman and Krueger (1991) found that two pollutants-sulphur dioxide and smoke-exhibited an inverted- $U$ shaped relationship. We found an inverted-U shaped relationship only between economic growth and sulphur dioxide emissions - a finding made also by Kaufmanna et al. (1998) and Markandya et al. (2006). The reason for this could be that we have controlled the consumption of coal, which captures a majority effect of economic growth on air pollution emissions.

The variable POPULATION is estimated to have opposite signs between the case of sulphur dioxide and smoke. The reason for this could be that population is not itself a decisive factor in air pollution emissions when we control the use of coal. 


\section{Table 17.4 Estimated results of the provincial dummy of the SUR model*}

\begin{tabular}{|c|c|c|c|c|c|c|}
\hline \multirow[b]{3}{*}{ Tianjin } & \multicolumn{2}{|c|}{$\mathrm{SO}_{2}$} & \multicolumn{2}{|c|}{ Smoke } & \multicolumn{2}{|c|}{ Indust } \\
\hline & Coefficient & P-value & Coefficient & P-value & Coefficient & P-value \\
\hline & $-74,712.42$ & 0.23 & $-20,084.44$ & 0.65 & $-71,001.17$ & 0.32 \\
\hline Hebei & $247,410.00$ & 0.12 & $218,990.70$ & 0.05 & $400,382.70$ & 0.03 \\
\hline Shanxi & $278,565.60$ & 0.08 & $-75,897.98$ & 0.50 & $-318,093.00$ & 0.08 \\
\hline Neimeng & $441,203.70$ & 0.00 & $-28,164.28$ & 0.79 & $-156,646.80$ & 0.35 \\
\hline Liaoning & $-10,285.15$ & 0.93 & $239,425.30$ & 0.00 & $257,120.80$ & 0.05 \\
\hline Jilin & $-15,106.05$ & 0.91 & $49,665.25$ & 0.59 & $-158,403.50$ & 0.28 \\
\hline Heilongjiang & $-218,583.70$ & 0.07 & $189,376.10$ & 0.03 & $-90,686.61$ & 0.51 \\
\hline Shanghai & $160,503.90$ & 0.03 & $-76,023.68$ & 0.15 & $-57,286.46$ & 0.50 \\
\hline Jiangsu & $-14,575.92$ & 0.93 & $219,807.00$ & 0.05 & $340,339.90$ & 0.05 \\
\hline Zhejiang & $-36,566.59$ & 0.72 & $139,597.00$ & 0.05 & $357,680.80$ & 0.00 \\
\hline Anhui & $50,817.54$ & 0.76 & $50,837.26$ & 0.66 & $52,659.95$ & 0.78 \\
\hline Fujian & $-41,882.53$ & 0.67 & $4,805.48$ & 0.95 & $48,122.38$ & 0.67 \\
\hline Jiangxi & $238,842.00$ & 0.12 & -463.16 & 1.00 & $-57,798.59$ & 0.74 \\
\hline Shandong & $227,807.40$ & 0.23 & $280,067.40$ & 0.04 & $473,812.70$ & 0.03 \\
\hline Henan & $-49,629.20$ & 0.81 & $441,930.90$ & 0.00 & $489,336.40$ & 0.04 \\
\hline Hubei & $141,033.80$ & 0.33 & $114,727.10$ & 0.27 & $106,951.40$ & 0.52 \\
\hline Hunan & $285,509.20$ & 0.07 & $250,142.70$ & 0.03 & $338,133.90$ & 0.06 \\
\hline Guangdong & $-12,313.66$ & 0.94 & $293,509.10$ & 0.01 & $580,014.50$ & 0.00 \\
\hline Guanxi & $607,458.40$ & 0.00 & $249,493.20$ & 0.02 & $117,233.20$ & 0.51 \\
\hline Hainan & $174,040.40$ & 0.22 & $-175,703.70$ & 0.08 & $-346,651.30$ & 0.03 \\
\hline Chongqing & $563,091.50$ & 0.00 & $-80,074.48$ & 0.44 & $-138,723.30$ & 0.40 \\
\hline Sichuan & $417,942.00$ & 0.03 & $530,490.10$ & 0.00 & $213,966.10$ & 0.34 \\
\hline Guizhou & $725,534.20$ & 0.00 & $-61,527.27$ & 0.63 & $-244,188.10$ & 0.24 \\
\hline Yunnan & $232,539.60$ & 0.13 & $-40,925.44$ & 0.71 & $-220,664.40$ & 0.21 \\
\hline Xizang & $359,338.70$ & 0.06 & $-285,079.70$ & 0.03 & $-481,698.40$ & 0.03 \\
\hline Shaanxi & $528,531.30$ & 0.00 & $43,023.70$ & 0.69 & $-91,783.74$ & 0.59 \\
\hline Guansu & $448,379.10$ & 0.01 & $-134,572.20$ & 0.26 & $-272,718.80$ & 0.16 \\
\hline Qinghai & $293,903.00$ & 0.08 & $-220,338.80$ & 0.06 & $-383,854.40$ & 0.04 \\
\hline Ningxia & $383,930.10$ & 0.02 & $-203,961.60$ & 0.08 & $-339,471.70$ & 0.07 \\
\hline Xinjiang & $181,035.40$ & 0.15 & $-71,052.97$ & 0.42 & $-162,888.40$ & 0.25 \\
\hline
\end{tabular}

* based on estimation results from specification 1.

Source: Author's own estimations. 
In term of regional diversity, several provinces achieve the same results as Beijing in all three emissions cases: Tianjin, Jilin, Anhui, Fujian, Jiangxi, Hubei, Yunnan and Xinjiang. No province differs from Beijing for all three emissions.

In the case of sulphur dioxide emissions, the level in Inner Mongolia, Shanghai, Guangxi, Chongqing, Sichuan, Guizhou, Shaanxi, Gansu and Ningxia are estimated significantly higher than Beijing, while only Helongjiang is estimated lower than Beijing (at 10 per cent significant level). It can be seen that western China performs worse than Beijing for sulphur dioxide emissions. This could be because Beijing started to promote the use of low-sulphur coal in 1998 (Cao 1998). In the case of smoke, Xizang (significant at the 5 per cent level), Qinghai, Ningxia and Henan (significant at the 10 per cent level) were all less polluted than Beijing. The majority of the remaining provinces were more polluted than Beijing. A similar pattern exists in the case of dust.

\section{Index decomposition results}

These results show that emission intensity has the biggest impact on emissions changes among all six factors during the period 1996-2006. As theory predicts, economic development and population growth are key factors driving the increase in emissions.

The decrease in smoke and dust emissions from 1996 to 2006 was due primarily to the decrease in emission intensities. In the case of sulphur dioxide emissions, even though overall emissions are increasing, emission intensity is decreasing and this has the most significant impact. The changing structure of coal among fossil-fuel energy and the energy mix also contributes to the decrease in emissions.

The fossil-fuel composition effect and the energy composition effect were mostly negative and were small for the entire period, except for a few years. The positive sign means that coal has recaptured some of its share of fossilfuel energy, which is due to the high demand for energy in recent years. The negative sign reflects the improvement in the atmospheric environment due to the switch from coal to other fossil-fuel energies and from fossil-fuel energy to non-fossil fuel energy; this impact is usually desirable. In contrast, however, the small value reveals a relatively weak impact on WGE changes from the change of fuel composition and the use of renewable energy, mainly because the composition of energy consumption is stable.

It is noteworthy that China's energy intensity increased from $0.37 \mathrm{~kg}$ of coal equivalent per renminbi (RMB) at the 1990 price (kgce/RMB) in 1997 to 0.55 $\mathrm{kgce} / \mathrm{RMB}$ in 2006 - an increase of 48.65 per cent for the period. As a result, the contribution of energy intensity to emissions increases is higher than that 
of traditional contributors such as economic development and population growth. The energy intensity effect results in increases in emissions of 947.65 Mt of sulphur dioxide, $512.16 \mathrm{Mt}$ of smoke and $438 \mathrm{Mt}$ of dust. The major reason for high and increasing energy intensity could be rapid industrialisation, which increases not only total energy consumption, but energy intensity. The biggest decrease in emission intensities occurred between 1998 and 1999, which might have been due to improvements in average coal quality when there was an oversupply of coal and consumers would not accept coal with high sulphur and ash content.

Compared with industrialised countries, where decreases in the aggregate energy intensity and aggregate carbon dioxide intensity are explained mainly by declines in energy intensity (Ang and Zhang 2000; Torvanger 1991), China's changes in industrial WGEs are to a large extent the result of the decline in coal emissions intensity.

To simplify the discussion, the results for the three WGEs are normalised to the year 1997. The cumulative change of emissions between 1997 and 2006 is decomposed to change each factor.

In all three cases, it is clear that the non-CEl increase of emissions is much higher than the real emissions, which demonstrates that the decreasing emission intensity is a significant contributor to emissions reduction. Energy intensity is next to emission intensity in terms of scale, but in the opposite direction. Differing from the findings in the literature (Shalizi 2007; Lin and Chang 1996), this study shows that energy intensity replaces economic growth as the major driver of increased emissions.

This result demonstrates that the real contribution of decreased emission intensity has been covered by the popular idea that emissions will be reduced by the decrease in energy intensity (Lin and Chang 1996; Shalizi 2007). This finding is significant because it shows another way of reducing emissions. If

Table 17.5 Summary of factors that affect the changes in sulphur dioxide, smoke and dust emissions, 1997-2006

\begin{tabular}{lccccccc}
\hline & $W G E$ & $W G E_{\text {E-effect }}$ & $W$ & & & & \\
SO2 & 322.80 & $-1,005.54$ & -53.83 & -25.98 & 947.65 & 311.02 & 148.70 \\
Smoke & -495.00 & $-1,212.90$ & -29.09 & -14.04 & 512.15 & 168.09 & 80.37 \\
Dust & -697.50 & $-1,311.46$ & -24.88 & -12.01 & 438.00 & 143.75 & 68.73
\end{tabular}

Source: Author's own summary. 


\section{Figure 17.3 Decomposition of sulphur dioxide emissions changes in China, 1997-2006}

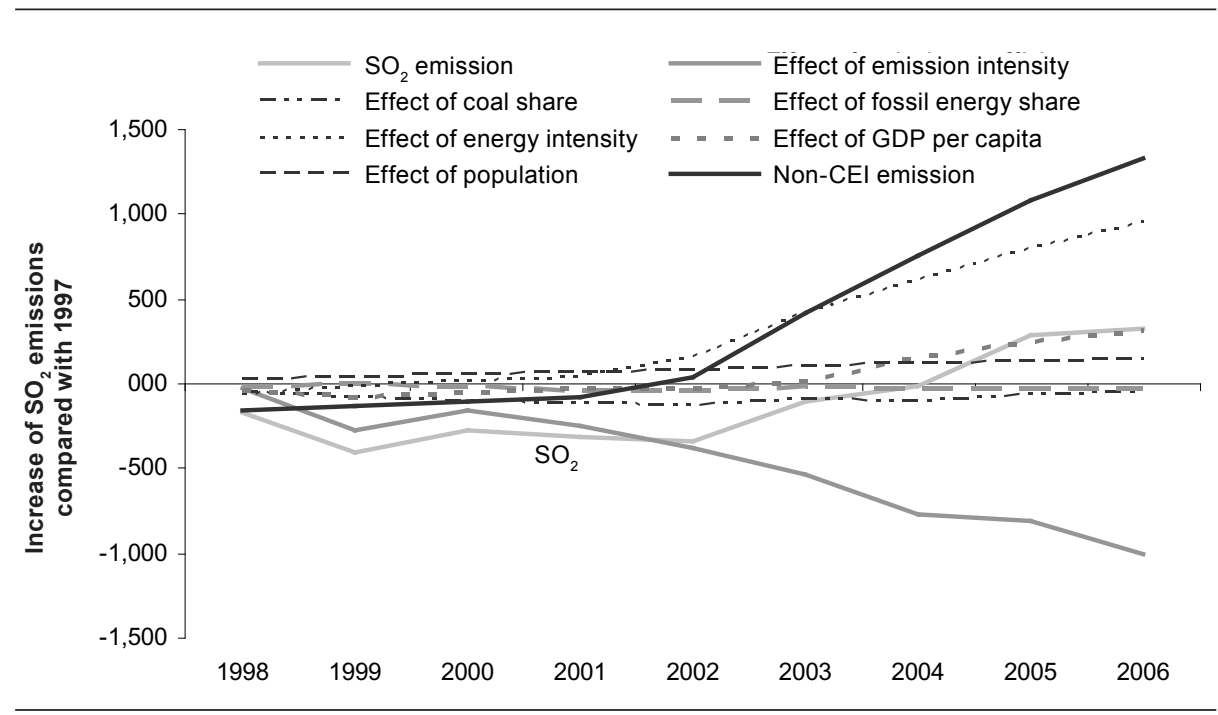

Source: Author's own calculations.

\section{Figure 17.4 Decomposition of smoke emissions changes in China, 1997-2006}

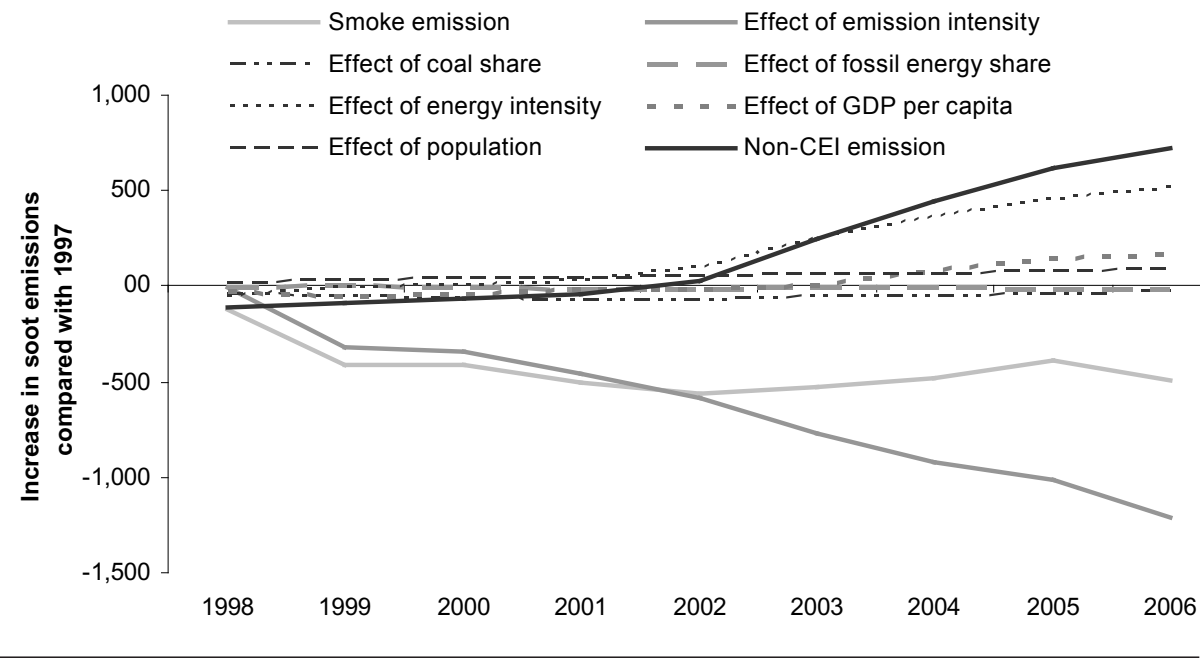

Source: Author's own calculations. 
Figure 17.5 Decomposition of dust emissions changes in China, 1997-2006

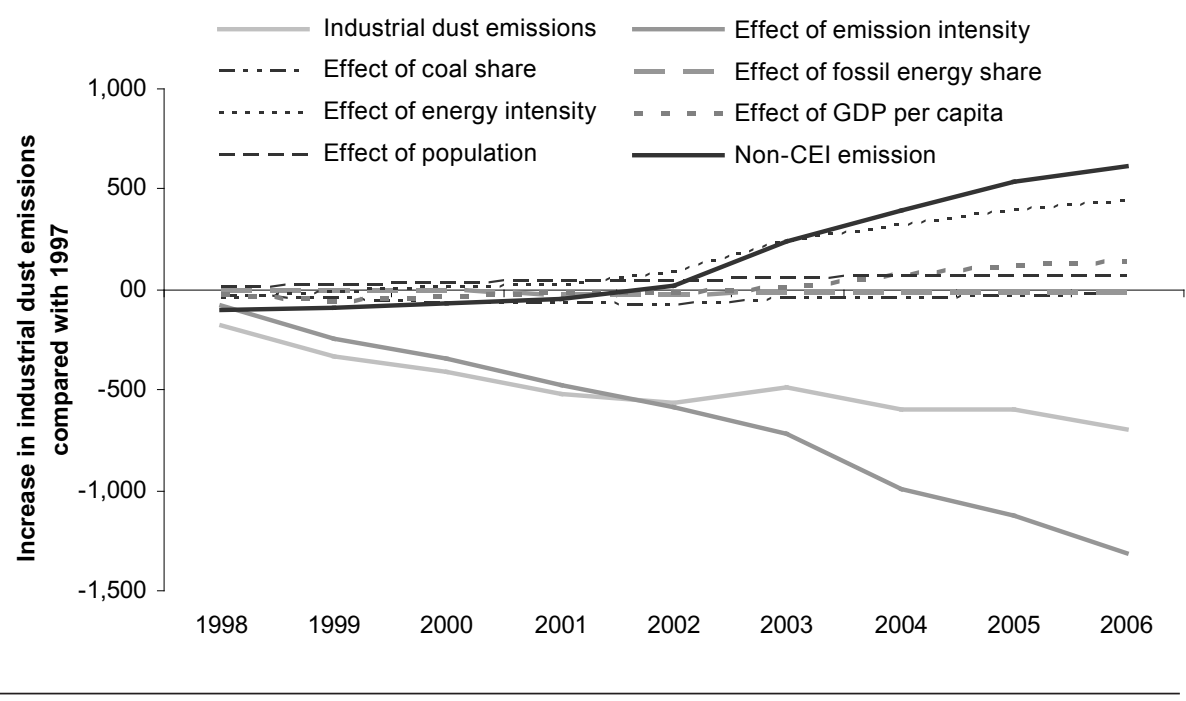

Source: Author's own calculations.

energy intensity could be reduced, as has happened in industrialised countries or as it was in China before 1998 (Figure 17.1), the decrease in China's WGEs could occur at double speed with the co-movement of these two drivers.

Reduced emission intensity is, however, found to be insignificant in China in the case of carbon dioxide in the decade after 1980, but has increasing significance in India in the 1990s, as reported by Shalizi (2007).

\section{Discussion: the role of technology}

It should be noted that the decrease in emission intensity of coal would not occur automatically. In some cases, this could be due to the switch from highsulphur to low-sulphur coal; however, the major contributor is technical change, which is stimulated more or less by environmental regulations.

The decrease in coal pollution has been achieved significantly through three basic methods: coal cleaning or washing, a pre-combustion method that can reduce sulphur content by as much as 30 per cent; post-combustion treatments, such as flue-gas desulphurisation (FGD) systems; and the use of electrostatic 
precipitators to remove airborne ash (National Energy Foundation 2007). The flue-gas clean-up systems that are available commercially and that have long been used in power plants can remove 99.95 per cent of particulates, 95 per cent of sulphur dioxide and 90 per cent of nitrogen oxides (Energy Committee of the ASME Council of Engineering 2005). Some of these methods, although straightforward now, seemed unrealistic in the 1970s when the US government started to introduce air-quality standards and regulations (EPA 1971).

Declining carbon dioxide emission intensity of coal is also technically possible, even though it has not yet been commercialised. Zero or near-zero emissions from coal-fired power plants are technologically feasible (Energy Committee of the ASME Council of Engineering 2005; Keay 2003; Shimkus 2005). Many international cooperation programs and some experimental projects have been initiated (IEA 2007). Carbon capture is thought most promising for integrated gasification combined-cycle (IGCC) coal-fired plants, even though the cost and reliability of IGCC have not been proved (Sachs, 2008). The 'FutureGen' project, which is dedicated to building near-zero emissions coal-fired power plants, is ready to demonstrate carbon dioxide capture and storage (CCS) technology on a commercial scale; integrated gasification combined-cycle (IGCC) coal power plants, which will be the cleanest coal-fired plants in the world, are expected to be operational in 2015 (DOE 2008). Rio Tinto and BP are working together on decarbonised energy projects, which can generate almost carbon-free electricity from coal (Macalister 2007). Further progress might mean that such techniques could be applied commercially. Carbon dioxide can also be separated and stored or put into other commercial use in the process of coal liquefaction. The Shenhua Group is cooperating with some oil companies to separate carbon dioxide and inject it into oil fields to increase the oil-recovery rate, which will be a double win: carbon dioxide will not be released into the atmosphere and more oil will be extracted from fields.

The Chinese government treats CCS technology seriously; it is documented in China's eleventh Five-Year Plan under the National High Technologies Program and in the National Medium and Long-Term Science and Technology Plan Towards 2020. The first 'green' power project, a 250-megawatt (MW) IGCC power station, located in Tianjin, is due to start operating by the end of 2009 (GreenGen 2008).

Since technology improvements provide ways for the coal industry to harmonise with the environment, it is important to popularise and utilise cleancoal technology to make coal use cleaner; it is also important to study and test CCS technology. 
One particular problem for China is not a shortage of feasible technology, but a lack of application-the result of insufficient incentives and external pressures. For example, most of China's electricity is produced from coal and most coal-fired plants are far dirtier than those found in Organisation for Economic Cooperation and Development (OECD) countries (IEA 2007). Although China has regulations for the installation of FGD requirements in power plants, in 2005, only 45 of 389 gigawatts (GW) of installed thermal capacity had an FGD unit installed, which helps explain why the target of the nation's tenth Five-Year Plan for a 10 per cent reduction in sulphur dioxide in 2005 compared with 2000 levels has not been achieved (IEA 2007).

As a cheaper alternative to FGD, coal washing has not been used well. Washed coal accounted for only 32 per cent of total coal consumption in 2005 (NDRC 2007b). Furthermore, coal-washing efficiency in China has achieved a removal rate of only 45 per cent (Watson et al. 2000). Since the use of washed coal depends on demand, it is necessary to create an institutional environment that stimulates and forces coal users-particularly large-scale users such as steel makers and power generators-to use washed coal.

Among conversion technologies, coal gasification has been used for the production of town gas and its increasing use is helping to reduce local air pollution in cities. This process is further extended to coal liquefaction, which provides a clean way to use coal. The technology is available and economical energy use has found increasing favour in recent years due to surging oil prices. Many Chinese companies are working to produce coal from oil, during the process of which polluting elements are separated and utilised and emissions are minimised. The Shenhua Group, the largest coal producer in China, with the best safety record, is building the first direct coal-to-oil plant. The plant aims to discharge zero pollution, other than carbon dioxide, and is dedicated to researching the technology of carbon dioxide capture and storage. The Shenhua Group and Southern African Sasol Energy Company Construction are planning to construct several indirect coal liquefaction plants for Shaanxi and Ningxia. The Shenhua Group plans to produce 100 million tonnes of coal to oil per annum by 2020 . Other liquefying technologies are also being tested. Furthermore, coal gasification will reduce a large amount of pollution from coal combustion. The Shenhua Group has launched the world's first coal-to-olefin plant in Baotou City, in the Inner Mongolia Autonomous Administration Region.

Improvements in combustion efficiency for large numbers of industrial boilers in China-where emissions reduction efficiency is just 65 per cent compared with 80 per cent in Europe (Watson et al. 2000) — could produce even more significant environmental benefits. 


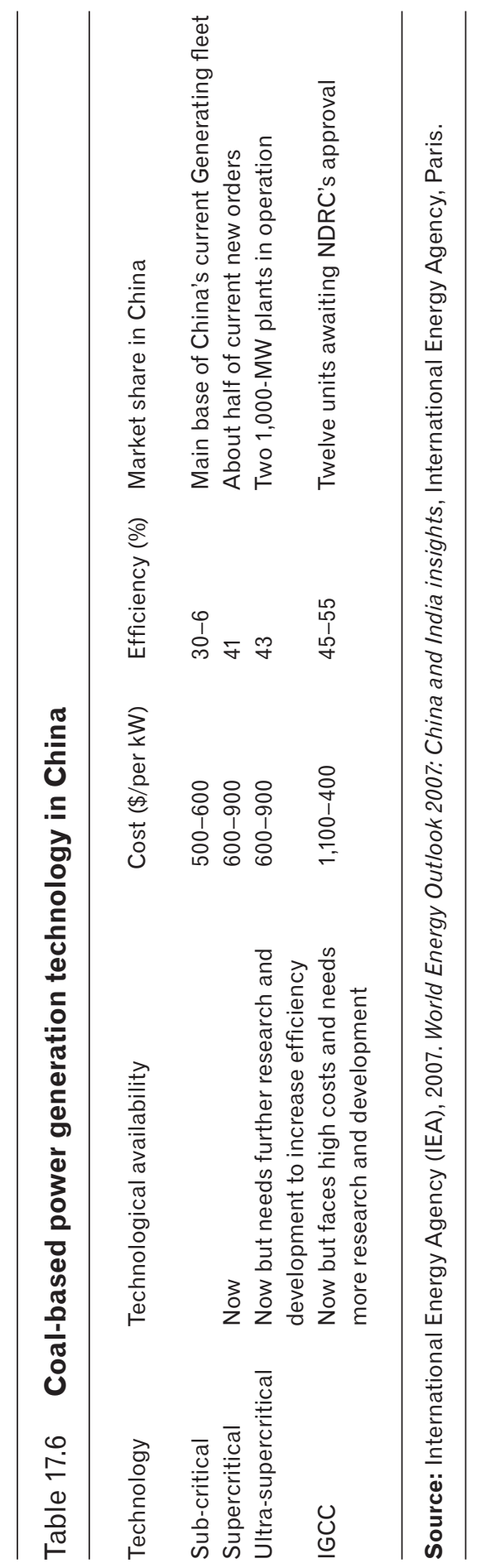




\section{Conclusion}

Relying on current technology, the continuing use of coal will create increased waste-gas and carbon dioxide emissions. The key factor in resolving the contradiction between environmental protection and coal industry development is to use coal in a clean way. This could take a long time; however, if it is possible, we must see a decline in WGE intensity from coal during the transitional process.

This research clarifies the misunderstanding that the same unit of coal will always cause the same amount of environmental pollution. The empirical analysis using the data for Chinese coal consumption and WGEs shows that there is a trend of declining WGE intensity, which is demonstrated by using two alternative methods. The index-decomposition method further demonstrated that declining emission intensity was the most important factor affecting overall WGEs. This study reveals that energy intensity in China has been increased and thus, besides of economic and population growth, has led to an increase in final emissions. With a fall in emission intensity, the coal industry can be developed while improvements are made to the environment-providing that emission intensity continues to fall without limit. Declining emission intensity, which is the key factor that alleviates the tension between the use of coal and the environment, has often been omitted from previous studies.

This finding sheds light on the future of the coal industry. In China's case, environmental regulations are needed and are welcome, even though they seem to impose some constraints on the coal industry's development initially. A harmonised future for the coal industry relies on the application of clean-coal technologies. The current coal-dominant pollution in China is due in part to insufficient use of available clean-coal technologies, such as coal washing and dust precipitation. With proper environmental regulations, China's environment can be improved because more clean-coal technologies will be applied. The confidence about the future of coal industry also comes from the fact that non-fossil alternatives have not been available in a necessary scale in the foreseeable future (Shi 2006).

The coal industry is not necessarily incompatible even with the worst-case scenario for the future: a carbon-constrained world. The biggest challenge for the future development of the coal industry is how to deal with carbon dioxide emissions and climate change. The technical possibilities have been explored. Energy and carbon prices can further accelerate the pace of technical application. If energy prices rise due to the scarcity of fossil-fuel resources, or a price is put on carbon emissions, these carbon dioxide reduction technologies will become economically viable and thus can lead to an accelerated occurrence of zero emission. 


\section{Notes}

1 This opinion is held by coal experts such as Yin Wu, director-general of the Energy Bureau at China's National Development and Reform Commission, Michael Han at Rio Tinto's Beijing representative office, and Weier Pan at the State Administration of Work Safety.

2 This system entailed: 1) designing anti-pollution measures; 2) constructing anti-pollution equipment simultaneously with the construction of industrial plants; and 3) operating antipollution equipment simultaneously with the operation of industrial plants.

3 The other national fundamental policy is aimed at controlling population growth.

4 In 2007, Jiangsu Province doubled its pollution discharge fees to 1.26 yuan $/ \mathrm{kg}$ for sulphur dioxide and to 1.2 yuan/kg for other WGEs (Jiangsu EPA 2007).

5 Total coal production dropped dramatically, which was magnified by the deliberate underreporting of production as a countermeasure against the national policy that caps output for each province. The initial reported output for 2000 was $998 \mathrm{Mt}$, which was corrected in 2006 to $1,299 \mathrm{Mt}$.

\section{References}

Ang, B.W. and Pandiyan, G., 1997. 'Decomposition of energy-induced $\mathrm{CO}_{2}$ emissions in manufacturing', Energy Economics, 19:363-74.

Ang, B.W. and Zhang, F.Q., 2000. 'A survey of index decomposition analysis in energy and environmental studies', Energy, 25:1149-76.

Ang, B.W., Zhang, F.Q. and Choi, K.-H., 1998. 'Factorizing changes in energy and environmental indicators through decomposition', Energy, 23:489-95.

Bao, Q. and Peng, S., 2006. 'Economic growth and environmental pollution: a panel data analysis', in R. Garnaut and L. Song (eds), The Turning Point in China's Economic Development, Asia Pacific Press and ANU E Press, The Australian National University, Canberra.

British Petroleum (BP), 2007. BP Statistical Review of World Energy.

Cao, Q., 1998. 'Beijing enforces the use of low sulfur coal', Living Time, Beijing.

Coal Enterprise Management, 2001. 'Coal industry is not a "sunset industry"', Coal Enterprise Management, 2001:5-9.

Darmstadter, J., 1999. 'Innovation and productivity in US coal mining', in R.D. Simpson (ed.), Productivity in Natural Resource Industries: improvement through innovation, Resources for the Future, Washington, DC.

Department of Energy (DOE), 2008. FutureGen Clean Coal Projects, US Department of Energy, Washington, DC.

Energy Committee of the ASME Council on Engineering, 2005. The Need for Additional US Coal-Fired Power Plants, ASME International.

Environmental Protection Agency (EPA), 1971. EPA Sets National Air Quality Standards, US Environmental Protection Agency, Washington, DC. 
Gray, W.B., 1987. 'The cost of regulation: OSHA, EPA and the productivity slowdown', American Economic Review:998-1006.

GreenGen, 2008. Development Plan of the GreenGen Co., The GreenGen Company, Beijing.

Grossman, G.M. and Krueger, A.B., 1991. Environmental impacts of a North American Free Trade Agreement, Working Paper 3914, National Bureau of Economic Research, Cambridge, Mass.

$\mathrm{He}, \mathrm{K} ., \mathrm{Huo}, \mathrm{H}$. and Zhang, Q., 2002. 'Urban air pollution in China: current status, characteristics and progress', Annual Review of Energy and the Environment:397-431.

Huang, Y., 2001. 'Coal will still be China's key energy in the $21^{\text {st }}$ century', China Energy, 3.

Intergovernmental Panel on Climate Change (IPCC), 2001. Special Report on Emissions Scenarios, Cambridge University Press, Cambridge.

International Energy Agency (IEA), 2007. World Energy Outlook 2007: China and India insights, International Energy Agency, Paris.

Jiangsu Provincial Environmental Protection Agency (Jiangsu EPA), 2007. Jiangsu Will Adjust Standards of Pollution Discharge Fees, Jiangsu Provincial Environmental Protection Agency, Nanjing.

Kaufmanna, R.K., Davidsdottira, B., Garnhama, S. and Paulyb, P., 1998. 'The determinants of atmospheric $\mathrm{SO}_{2}$ concentrations: reconsidering the environmental Kuznets curve', Ecological Economics, 25:209-20.

Kaya, Y., 1990. Impact of carbon dioxide emission control on GNP growth: interpretation of proposed scenarios, Presented to the Intergovernmental Panel on Climate Change Energy and Industry Subgroup, Response Strategies Working Group, Paris.

Keay, M., 2003. 'The view from Europe-and elsewhere', Oxford Energy Forum, 52. $\mathrm{Li}, \mathrm{J} ., 2003$. 'Coal industry is not a "sunset industry"', Journal of Coal Economics Research, 2003:10-12.

Liang, D. and Zhou, Y., 2008. 'Waste gas emission control and constraints of energy and economy in China', Energy Policy, 36:268-79.

Lin, S.J. and Chang, T.C., 1996. 'Decomposition of $\mathrm{SO}_{2}, \mathrm{NO}_{x}$ and $\mathrm{CO}_{2}$ emissions from energy use of major economic sectors in Taiwan', The Energy Journal, 17:1-17.

Macalister, T., 2007. 'Rio Tinto and BP plan project to clean up', The Guardian. Markandya, A., Golub, A. and Pedroso-Galinato, S., 2006. 'Empirical analysis of national income and $\mathrm{SO}_{2}$ emissions in selected European countries', Environmental and Resource Economics, 35:221-57. 
National Bureau of Statistics (NBS), various years. China Statistical Yearbook, China Statistics Press, Beijing.

National Development and Reform Commission (NDRC), 2007a. China's National Climate Change Program, National Development and Reform Commission, Beijing.

- - 2007b. Opinions on work towards energy conservation and emission reduction in the coal industry, National Development and Reform Commission, Beijing.

National Energy Foundation, 2007. Coal and the Environment, National Energy Foundation, Beijing.

Sachs, J.D., 2008. 'Keys to climate protection (extended version)', Scientific American Magazine, 18 March.

Shadbegian, R. and Gray, W., 2006. 'Assessing multi-dimensional performance: environmental and economic outcomes', Journal of Productivity Analysis, 26:213-34.

Shalizi, Z., 2007. Energy and Emissions: local and global effects of the rise of China and India, World Bank, Washington, DC.

Shi, X., 2003. 'The future of the coal industry under the context of strict environmental regulations', Journal of Coal Economics Research, 2003:6-11.

- - 2006. 'Harmonising the coal industry with the environment', in R. Garnaut and L. Song (eds), The Turning Point in China's Economic Development, Asia Pacific Press and ANU E Press, The Australian National University, Canberra.

Shimkus, J., 2005. Press release from the office of Congressman John Shimkus, 14 September.

Shrestha, R.M. and Timilsina, G.R., 1997. ' $\mathrm{SO}_{2}$ emission intensities of the power sector in Asia: effects of generation-mix and fuel-intensity changes', Energy Economics, 19:355-62.

State Council, 1998. 'Official reply of the State Council concerning acid rain control areas and sulfur dioxide pollution control areas', Guohan, 5.

State Environmental Protection Administration (SEPA), 1982. National Ambient Air Quality Standards, State Environmental Protection Administration.

- -, 1996-2006. State Public Release of Environmental Protection, State Environmental Protection Administration.

- - various years. China Environmental Yearbook, China Environmental Yearbook Press, Beijing.

State News Office, 2006. Environmental Protection in China (1996-2005), Beijing. 
Torvanger, A., 1991. 'Manufacturing sector carbon dioxide emission in nine OECD countries, 1973-87', Energy Economics, 13:168-86.

Viguier, L., 1999. 'Emissions of $\mathrm{SO}_{2}, \mathrm{NO}_{x}$ and $\mathrm{CO}_{2}$ in transition economies: emission inventories and Divisia index analysis', Energy Journal, 20:59-87.

Wang, C., Chen, J. and Zou, J., 2005. 'Decomposition of energy-related $\mathrm{CO}_{2}$ emissions in China: 1957-2000', Energy, 30:73-83.

Wang, Q., 1999. 'Coal industry is not a "sunset industry"', China Coal, 25:7-9.

Wang, X. and Feng, Z., 2003. 'Energy consumption with sustainable development in developing countries: a case in Jiangsu, China', Energy Policy, 31:1679-84.

Watson, J., Xue, L., Oldham, G., Mackerron, G. and Thomas, S., 2000. International Perspectives on Clean Coal Technology Transfer to China, Final Report to the Working Group on Trade and Environment, China Council for International Cooperation on Environment and Development, Beijing.

Wu, L., Kaneko, S. and Matsuoka, S., 2006. 'Dynamics of energy-related $\mathrm{CO}_{2}$ emissions in China during 1980 to 2002: the relative importance of energy supply-side and demand-side effects', Energy Policy, 34:3549-72.

\section{Acknowledgment}

The author acknowledges the financial support for my $\mathrm{PhD}$ research provided through the Rio Tinto-ANU China Partnership. 